East African Medical Journal Vol. 78 No. 8 August 2001

FRACTURES OF THE LATERAL CONDYLE OF THE HUMERUS IN CHILDREN

M. Jenyo, FRCS, Eng, Consultant Orthopaedic Surgeon, Asir Central Hospital, Abha, Saudi Arabia and T, Mirdad, M.D., FRCSC, Associate Professor of Orthopaedic Surgery, College of Medicine, King Khalid University, Abha, Kingdom of Saudi Arabia

Request for reprints to: Professor T. Mirdad, College of Medicine, King Khalid University, P.O. Box 641, Abha Kingdom of Saudi Arabia

\title{
FRACTURES OF THE LATERAL CONDYLE OF THE HUMERUS IN CHILDREN
}

\author{
M. JENYO and T. MIRDAD
}

\begin{abstract}
Background: Conservative treatment of fractures of the lateral humeral condyle in children is associated with many problems as noted previously by several authors.

Objective: To determine the outcome of internal fixation of fractures of the lateral humeral condyle.

Design: A prospective study.

Setting: Department of Orthopaedic Surgery, Asir Central Hospital, Abha, Saudi Arabia, between 1991 and 1998.

Subjects: Sixteen children with fracture of the lateral humeral condyle. All were admitted via the Emergency Room and comprised 14 boys and two girls. Ages ranged between two and 11 years.

Interventions: All the patients had some form of internal fixation. Percutaneous Kirschner $\mathrm{K}$ - wire fixation was done for the undisplaced and minimally displaced fractures and open reduction and $\mathrm{K}$-wire fixation for the widely displaced and rotated fractures. One patient developed non-union of the lateral condyle fracture that required bone grafting and internal fixation with lag screw.

Main outcome measures: Enhancement of union and reduction of complications resulting from conservative treatment of the fractures.

Results: Out of the sixteen cases, there was one case with a minor degree of mal-union on account of loose $\mathrm{K}$-wire and one case with non-union following open reduction and internal fixation.

Conclusion: The authors recommend internal fixation of all fractures of the lateral humeral condyle in children irrespective of the degree of displacement.
\end{abstract}

\section{INTRODUCTION}

In a combined series of 5228 fractures of the distal humerus, fractures of the lateral condyle of the humerus account for only $16.9 \%$, with the average age being around six years(1). Open reduction and internal fixation are necessary for displaced fractures. The treatment of nondisplaced and minimally displaced fractures remain controversial(2,3). As early as 1975 , Jakob et al (4) had argued in favour of surgery on all these fractures.

Closed reduction and percutaneous pinning has been recommended for lateral humeral condylar fractures with less than $2 \mathrm{~mm}$ displacement $(5,6)$. Severe complications (mal-union, non-union) occur in patients who are treated without operation(7), whilst inadequate treatment continues to be the leading cause of non-union of slightly displaced lateral humeral condyle fractures in paediatric patients $(8)$. We report on our experience with internal fixation in children from our centre.

\section{MATERIALS AND METHODS}

The case files and $X$-ray films of sixteen patients treated in Asir Central Hospital, Abha, Saudi Arabia between 1991 and 1998 for fractures of the lateral condyle of the humerus were reviewed. All patients presentef within twenty four hours of injury and all were operated on within forty eight hours; percutaneous $\mathrm{K}$-wire fixation for the undisplaced or minimally displaced ( 6 cases) and open reduction and $\mathrm{K}$-wire fixation for the widely displaced and rotalch fractures ( 10 cases). The $\mathrm{K}$ wires were left outside the skin. The classification of Jakob et al(4) was used, namely: undisplaced, moderately displaced, completely displaced and rotated with undisplaced fracture being taken as one without displacement whilst minimally displaced had $2 \mathrm{~mm}$ or less of displacement. Displaced fractures had more than $2 \mathrm{~mm}$ of displacement.

Plain $x$-ray films: Antero-posterior, lateral and internal oblique views were taken of the corresponding elbow. No arthrography or CT scan or stress vicws were done. Post operatively an above elbow plastcr of Paris posterior slab was applied for six weeks. K-wires were removed in the outpatient clinic without anaesthesia six wets sfifor surgery. Following K- 
wire removal, children were started on physiotherapy applying only active exercises. No post operative elbow manipulation was performed following the removal of the $\mathrm{K}$-wires fearing the development of myositis ossificans.

\section{RESULTS}

Table 1 shows features in all the cases seen. The ages of the patients ranged between two and eleven years. There were 14 boys and two girls. The right elbow was affected in ten of the cases whilst the left was involved in six. None of the cases had bilateral injury.

Most of the patients were followed up for between two and three years after operation. One patient (case No. 14) developed a minor degree of mal-union (cubitus valgus) on account of loose $\mathbf{K}$-wires. One patient (case No. 16 ) developed non-union with cubitus valgus after open reduction and internal fixation for widely displaced and rotated fracture at the age of six years, using the lateral approach. None of the cases developed avascular necrosis and none had associated neuro-vascular injury. On follow up, twelve children regained full range of elbow motion. Three children developed about $10^{\circ}$ of elbow extension lag but with full flexion and no functional disability. The child who suffered from non-union of the fracture and needed bone grafting and revision of internal fixation developed persistent elbow stiffness with a range of motion between $45^{\circ}$ (extension lag) and $120^{\circ}$.

We had two cases of pin tract infection in these 16 cases, but nodeep infection was encountered. The infection in these two cases cleared after removal of the $\mathrm{K}$-wires. Figures 1 and 2 show a minimally displaced and a moderately displaced fracture respectively, which were fixed percutaneously with two $K$-wires each, both of which eventually under went good union. Figure 3 shows a widely displaced and rotated fracture that was openly reduced (lateral approach) and internally fixed with two $\mathrm{K}$-wires and which finally healed well.

Table 1

Analysis of the 16 cases of the lateral humeral condyle fractures in children

\begin{tabular}{|c|c|c|c|c|c|}
\hline $\begin{array}{l}\text { Serial } \\
\text { No. }\end{array}$ & $\begin{array}{l}\text { Age in } \\
\text { years }\end{array}$ & Sex & Side & Treatment & Complication \\
\hline 1 & 6 & $\mathbf{M}$ & $\mathrm{L}$ & Percut. K-wire fixation & None \\
\hline \multirow[t]{2}{*}{2} & $51 / 2$ & $\mathbf{M}$ & $\mathbf{L}$ & Closed reduction & \\
\hline & & & & and Percut $K$-wire fixation & $"$ \\
\hline 3 & 2 & $\mathbf{M}$ & $\mathbf{R}$ & Percut. K-wire fixation & $"$ \\
\hline \multirow[t]{2}{*}{4} & 8 & $\mathbf{M}$ & $\mathrm{R}$ & ORIF (lateral approach). & \\
\hline & & & & $\mathrm{K}$-wire fixation & $"$ \\
\hline 5 & 3 & $\mathbf{M}$ & $\mathbf{R}$ & ORIF (Iateral approach), K-wire fixatıon & $"$ \\
\hline 6 & 3 & $\mathbf{M}$ & $\mathrm{R}$ & ORIF (lateral approach), K-wire fixation & $n$ \\
\hline 7 & 3 & $\mathbf{M}$ & $L$ & ORIF (lateral approach), K-wire fixation & $"$ \\
\hline 8 & 7 & $\mathbf{M}$ & $\mathbf{R}$ & ORIF (lateral approach), K-wire fixation & 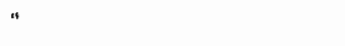 \\
\hline 9 & 4 & $\mathbf{M}$ & $\mathbf{R}$ & ORIF (lateral approach), K-wire fixation & $"$ \\
\hline 10 & 5 & $\mathbf{F}$ & $\mathrm{L}$ & ORIF (lateral approach), K-wire fixation & $"$ \\
\hline 11 & 11 & $\mathbf{M}$ & $\mathbf{R}$ & Percut. K-wire fixation & $"$ \\
\hline 12 & 6 & $\mathbf{M}$ & $\mathrm{R}$ & ORIF (lateral approach), K-wire fixation & $"$ \\
\hline 13 & 8 & $\mathbf{M}$ & $R$ & Percut. K-wire fixation & $"$ \\
\hline 14 & 4 & $\mathbf{F}$ & $R$ & Percut. K-wire fixation & $\begin{array}{l}\text { Minimal mal-union (cubitus } \\
\text { valgus) }\end{array}$ \\
\hline 15 & $61 / 2$ & $\mathbf{M}$ & $\mathrm{L}$ & ORIF (lateral approach), K-wire fixation & None \\
\hline 16 & 6 & $\mathbf{M}$ & L & ORIF (lateral approach), K-wire fixation & $\begin{array}{l}\text { Non-union treated by two } \\
\text { cancerous screws and bone } \\
\text { graft. Mal-union (cubitus } \\
\text { valgus) }\end{array}$ \\
\hline
\end{tabular}

$\mathrm{M}=$ Male, $\mathrm{F}=$ Female, $\mathrm{L}=$ Left, $\mathrm{R}=$ Right, $\mathrm{ORIF}=$ Open reduction internal fixation, $\mathrm{K}=$ Kirschner wire, Percut $=$ Percutancous 
Figure 1

$X$-ray films of $(R)$ elbow of a two-year old male showing a minimally displaced fracture of lateral humeral condyle

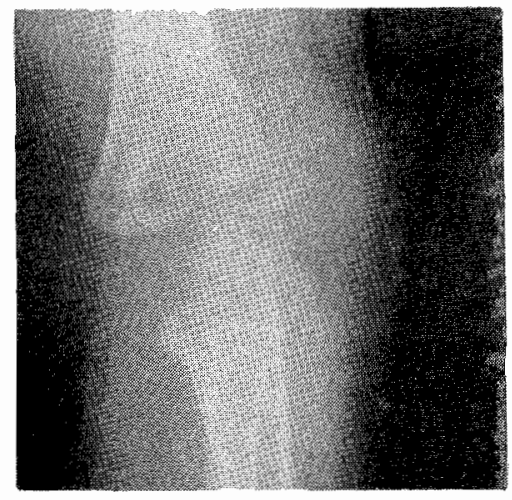

(a) AP view pre-op

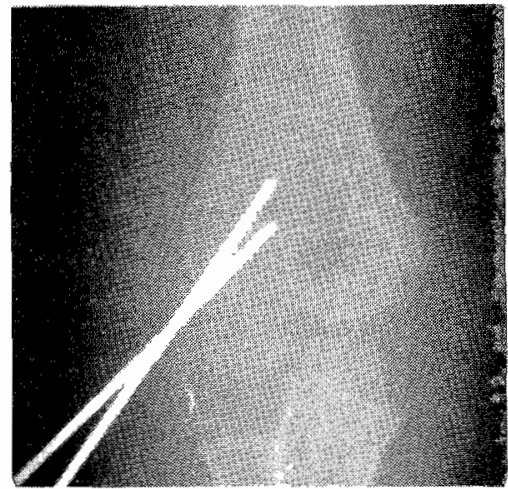

(c) AP view post-op after $\mathrm{K}$ wire fixation percutaneously

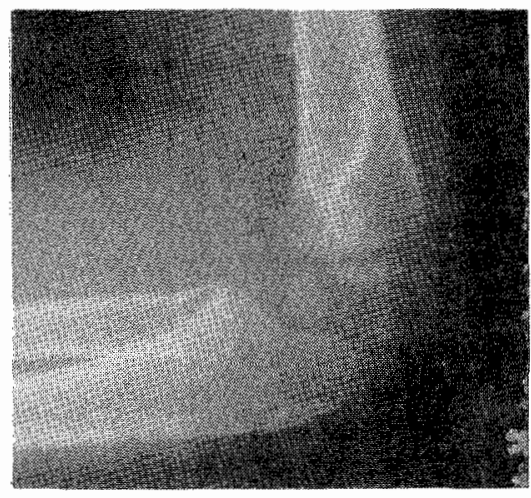

(b) Lat. view pre-op

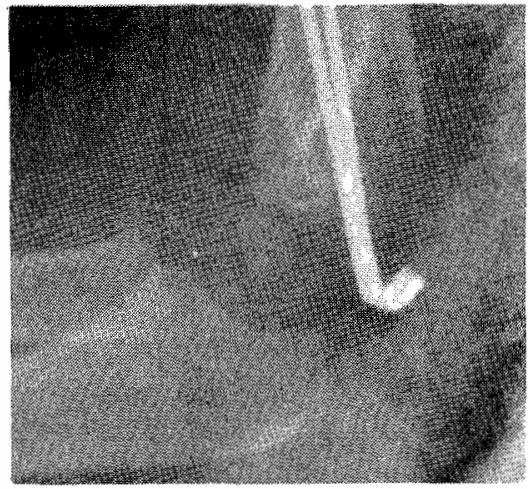

(d) Lat. view post-op after $\mathrm{K}$ wire fixation percutaneously

Figure 2

$X$-ray films of $(R)$ elbow of an eleven-year old boy showing a moderately displaced fracture of lateral humeral condyle

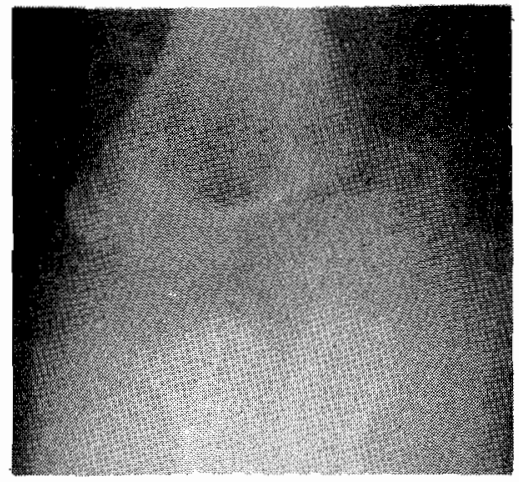

(a) AP view pre-op

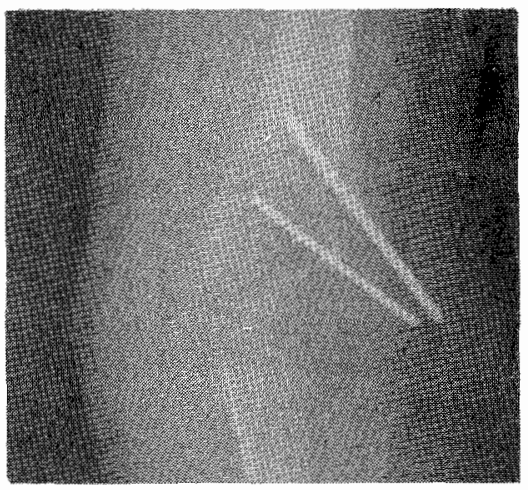

(c) AP view after percutaneous $K$ wire fixation

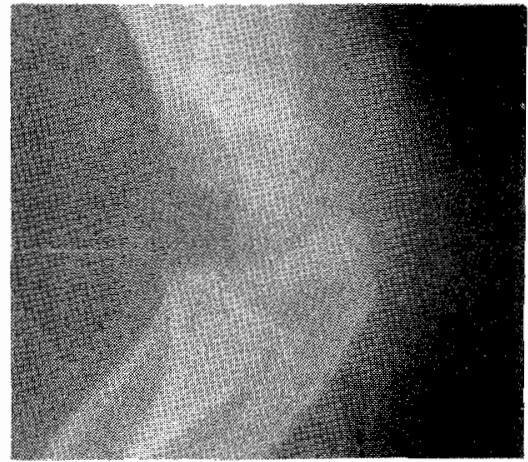

(b) Lat. view pre-op

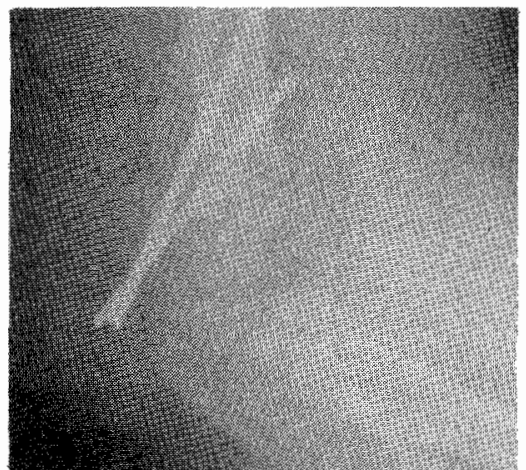

(d) Lat. view after percutaneous $\mathrm{K}$ wire fixation 


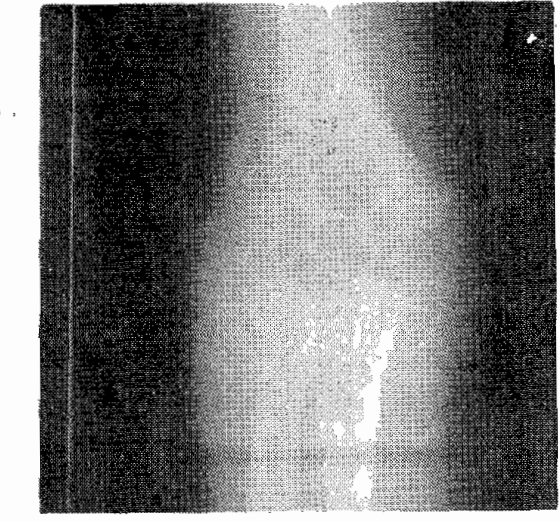

(e) AP view after removal of $\mathrm{K}$ wires

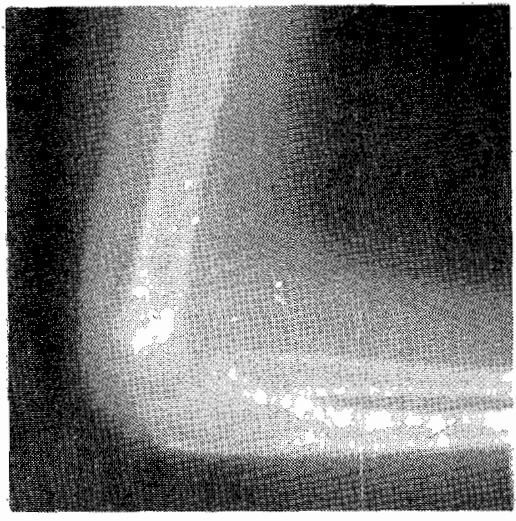

(f) Lat. view after removal of $\mathrm{K}$ wires

Figure 3

$X$-ray films of $(L)$ elbow of a six and half-year old boy showing a widely displaced and rotated fracture of lateral humeral condyle

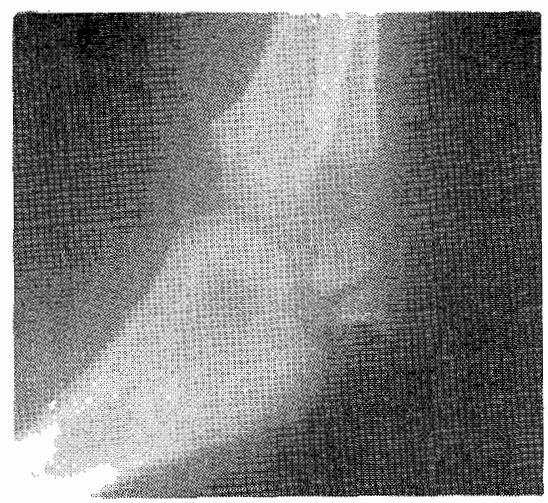

(a) AP view pre-op

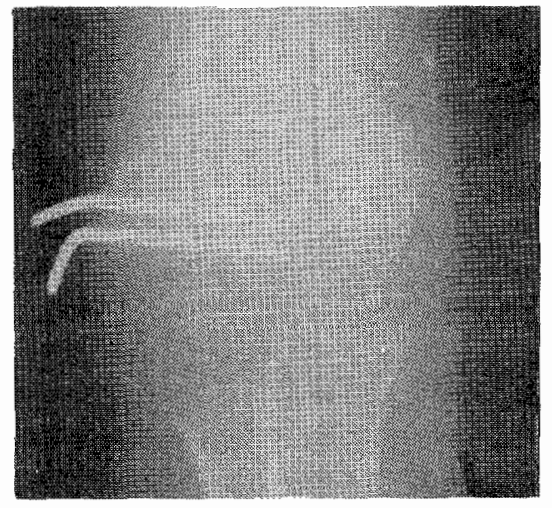

(c) AP view after open reduction and $\mathrm{K}$ wire fixation

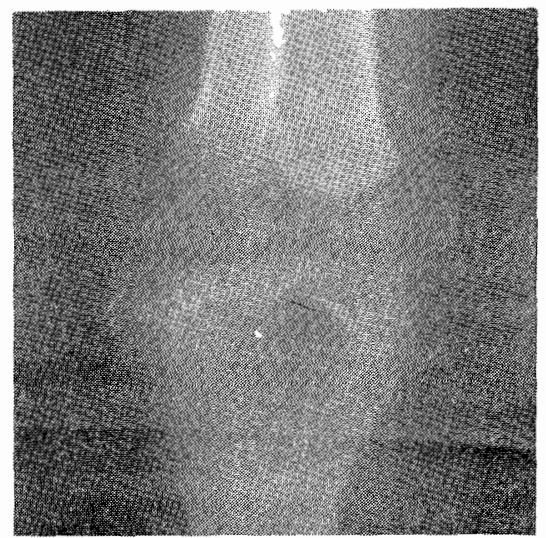

(e) AP view after removal of $\mathrm{K}$ wires

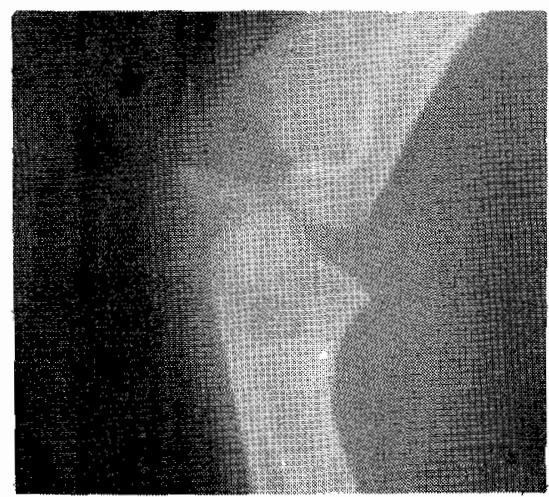

(b) Lat view pre-op

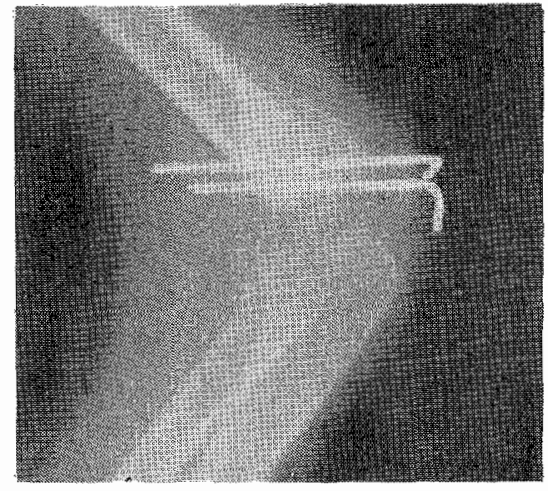

(d) Lat, view after open reduction and $\mathrm{K}$ wire fixation

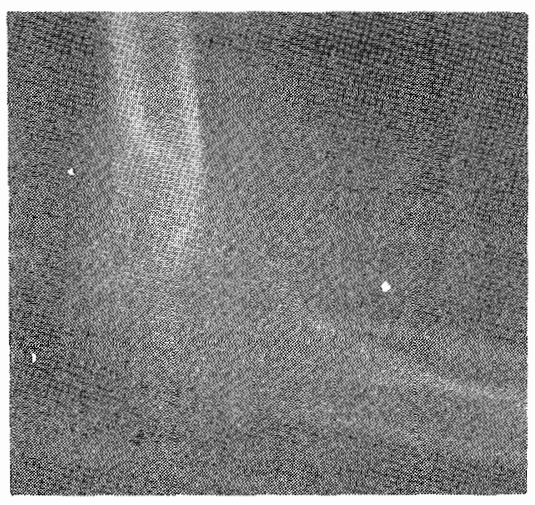

(f) Lat. view after removal of $\mathrm{K}$ wires 


\section{Figure 4}

$X$-ray films of $(L)$ elbow of a fourteen year old boy showing old nom-union of fracture of lateral humeral condyle with cubitus vulgus; initial open reduction was done at age of six years

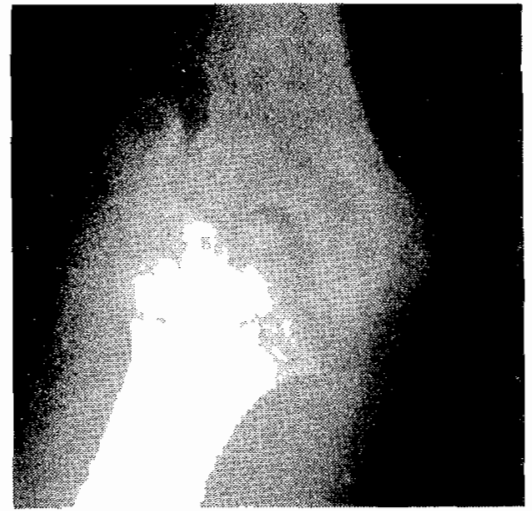

(a) AP view pre-op (old fracture non-union) at age 14 years

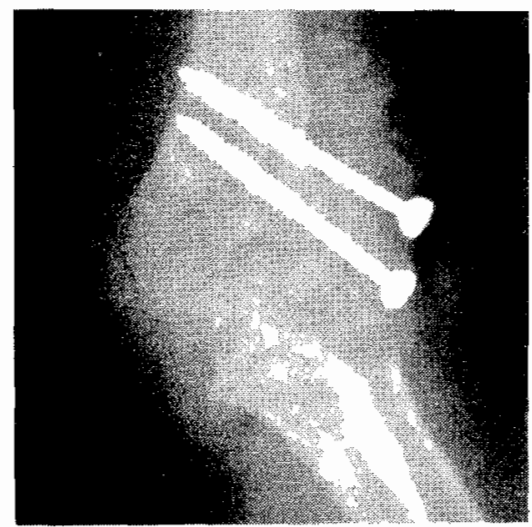

(c) AP view post cancellous screw fixation and bone grafting at age of 14 years

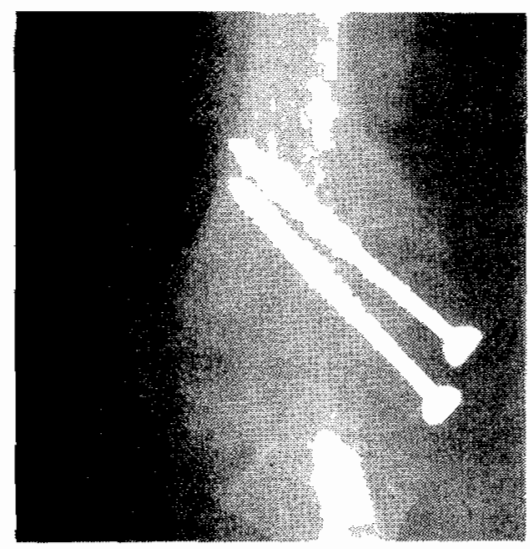

(e) AP view showing adequate healing at age 15 years

Figure 4 shows a case of old-fracture non-union at the age of 14 years following open reduction (via lateral approach) and internal fixation with $\mathrm{K}$-wires at the age of six years. Unfortunately, the $x$-rays of the initial fixation done at the age of six years, when the fracture was fresh, are missing. In situ fixation with two cancellous screws, coupled with cancellous bone graft was performed at the

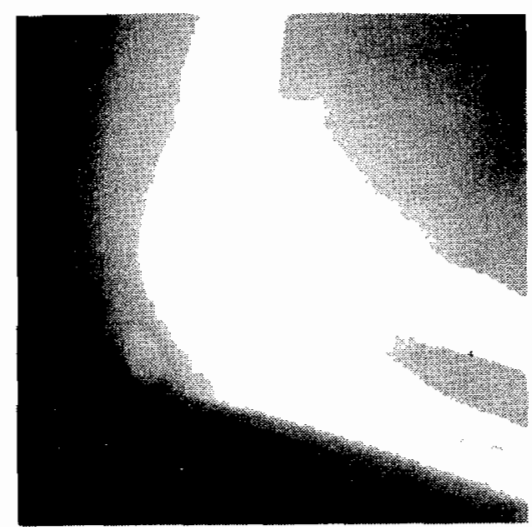

(b) Lat. view pre-op (old fracture non-union) at age 14 years

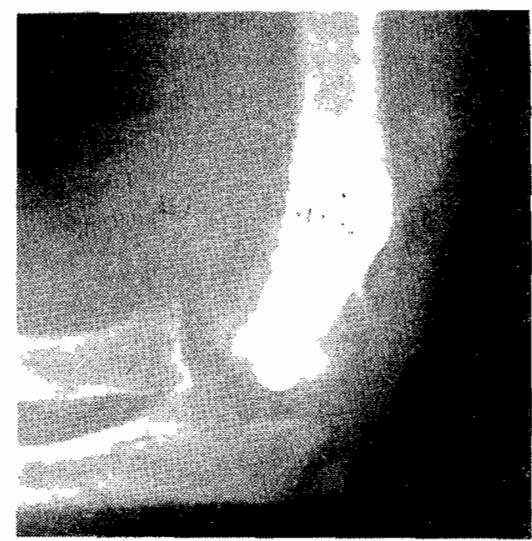

(d) Lat. view after post cancellous screw fixation and bone grafting at age of 14 years

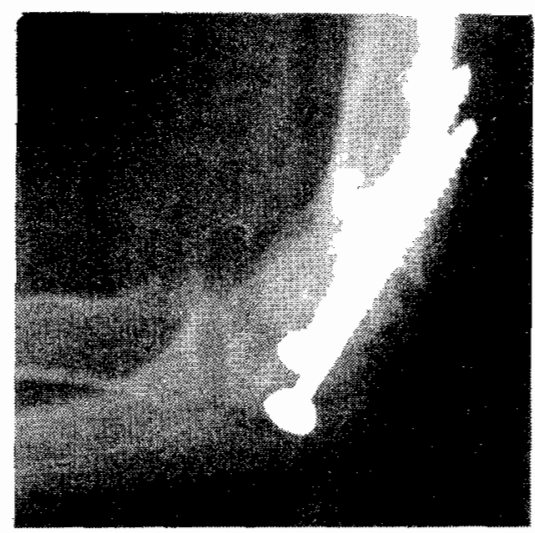

(f) Lat. view showing adequate healing at age 15 years

age of 14 years. Although the patient had cubitus valgus the fracture finally united without ulnar nerve palsy.

Out of sixteen cases, there was only one case with a minor degree of mal-union on account of loose $\mathrm{K}$-wires and one case of non-union following open reduction and internal fixation. In practice the result was unsatisfactory in only one case $(6.25 \%)$ with non-union which is acceptable. 


\section{DISCUSSION}

The diagnosis of fracture of the lateral condyle of the humerus is usually fairly straight forward. It is the details regarding displacement and stability that is a problem and ancillary methods of investigation for better definition include good plain $\mathrm{x}$-ray (antero posterior, lateral, internal oblique); arthrography(9); stress valgus and varus $x$-rays, (displacement on stress view signifying absence of intact cartilaginous hinge) and CT scan.

While some conclude that non-displaced and minimally displaced fractures of the lateral condyle of the humerus generally have a good prognosis (10), others have expressed concern about subsequent displacement. Advocates of conservative (non-operative was cast immobilisation alone) treatment for non-displaced or minimally displaced fractures are quick to warn that these fractures should be followed up closely for the first two weeks after injury as subsequent displacement frequently occurs within the first few days following trauma, especially between the sixth and the ninth day(3).

Additional evidence that internal fixation of fractures of the lateral humeral condyle is justified can be deduced from the work of Thonell et al(11) who found that displacement whilst still in plaster of Paris cast occurred in $2.6 \%$ of fractures classified as stable, $24.1 \%$ of fractures classified as ambiguous and $44.4 \%$ of fractures classified as unstable.

Immobilisation to union has been reported to vary between four and twelve weeks $(3,7,12)$. Most of our fractures had healed by eight weeks; K-wires being removed at six weeks. Delayed union may follow external immobilisation alone or inadequate internal fixation and may be related to the degree of displacement. In a ten-year study of thirty one children with fresh fractures of lateral humeral condyle, Flynn et al (13) discovered that those fractures that healed rapidly had $2 \mathrm{~mm}$ or less of initial displacement while those that did not heal had an average of $3 \mathrm{~mm}$ or more of initial displacement.

The lateral approach is an excellent procedure to fractures of the lateral humeral condyle because the common origin of the extensor muscles is attached to the condylar fragment and need not be disturbed(14). All our openly reduced fractures were via the lateral approach. Several alternative materials for internal fixation of this fracture are available: sutures (which are obviously inadequate), K-wire, screw, and biodegradable material (Polyglycolic Acid (PGA))(15). The advantage of biodegradable materials lies in the fact that a second operation to remove the implant is avoided. The disadvantage is related to the fact that growth factor of bone is much greater than the strength of PGA making it susceptible to spontaneous breakage.
Rutherford(16) in a review of thirty nine cases of fracture of the lateral humeral condyle in children discovered that epiphyseal arrest was rare (one patient out of thirty nine) and that fish-tail deformity of the distal humerus occurred commonly when mal-reduction was present. None of these complications were seen in our series.

On account of the paucity of major complications $(6.25 \%)$ of internal fixation of all paediatric lateral humeral condyle fractures in our series (Table 1 and 2), our results support the literature in encouraging internal fixation of these fractures, regardless of their displacement. Internal fixation of all fractures of lateral humeral condyle in children whatever the degree of displacement is worth the effort and has some merit.

\section{REFERENCES}

1. Rockwood C.A. Jr., Wilkins KE. and Beaty J.H. Fractures in children, 4th Edition, Vol. 3. Chapter 10, pages 656 and 752 , Lippincott-Raven Publishers, 1996.

2. Beaty J.H. and Wood A.B. Fractures of the lateral humeral condyle in children. Presented at the Annual Meeting of the American Academy of Orthopaedic Surgeons, Las Vegas, January 18, 1985

3. Bast S.C., Hoffer M.M. and Aval S. Non-operative treatment for minimally and non-displaced lateral humeral condyle fractures in children. J. Paediat. Orthop. 1998; 18:448-50.

4. Jakob R., Fowles JV., Rang M. and Kassab, M.T. Observations concerning fractures of the lateral humeral condyle in children. J Bone Jt Surg. Brit. 1975; 57: 430-6.

5. Mintzer C.M., Waters P.M., Brown D.J. and Kasser J.R. Percutaneous pinning in the treatment of displaced lateral condyle fractures. J. Paediat. Orthop. 1994; 14:462-5.

6. Foster D.E., Sullivan J.A. and Gross R.H. Lateral humeral condylar fractures in children. J. Paediat. Orthop. 1985; 5:16-22.

7. Papavasiliou V.A. and Beslikas T.A. Fractures of the lateral humeral condyle in children: an analysis of 39 cases. Injury 1985; 16: 364-6.

8. Flynn J.C. Non-union of slightly displaced fractures of the lateral humeral condyle in children: an update. J. Paediat. Orthop. 1989; 9:691-6.

9. Marzo J.M., d'Amato C., Strong M. and Gillespie R. Usefulness and accuracy of arthrography in management of lateral humeral condyle fractures in children. J. Paediat. Orthop. 1990;10:317-21.

10. Jeffrey R.S. Injuries of the lateral humeral condyle in children. J. Roy Coll. Surg. Edinb. 1989; 34:156-9.

11. Thonell S., Mortensson W., Thomasson B. Prediction of the stability of minimally displaced fractures of the lateral humeral condyle. Acta Radiol. 1988; 29:367-70.

12. Flynn J.C. and Richards J.F. Jr. Non-union of minimally displaced fractures of the lateral condyle of the humerus in children. J. Bone Jt Surg. Amer. 1971; 53:1096-101.

13. Flynn J.C., Richards J.F. Jr. and Saltzman R.I. Prevention and treatment of non-union of slightly displaced fractures of the lateral humeral condyle in children. An end-result study. J. Bone Jt. Surg. Amer. 1975; 57:1087-92.

14. Canale S.T. In: Campbell's Operative Orthopaedics 9th Edition, Vol 1, Chapter 2, 121-8, Mosby Year Book Inc. 1998 St Louis.

15. Makela E.A., Bostman O., Kekomaki M., Sodergard J., Vainio J., Tormala P. and Rokkanen P. Biodegradable fixation of distal humeral physeal fractures. Clin. Orthop. 1992; 283:237-43.

16. Rutherford A. Fractures of the lateral humeral condyle in children. $J$. Bone Jt Surg. Amer. 1985; 67:851-6. 